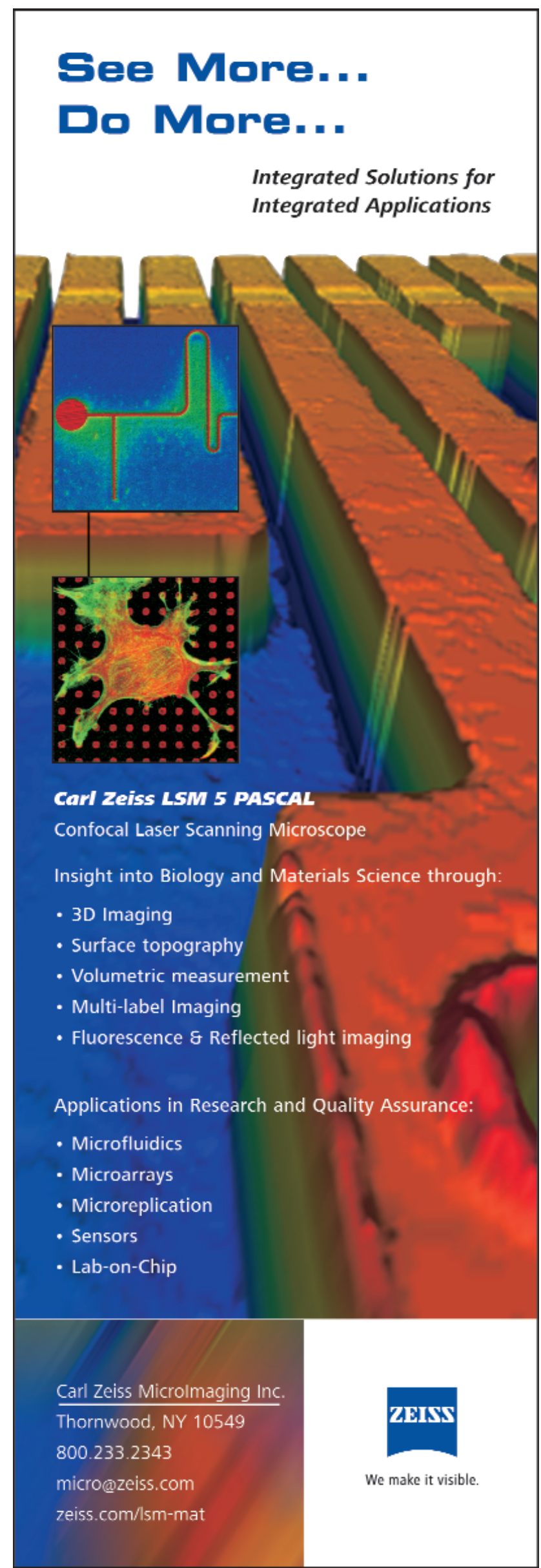

For more information, see http://advertisers.mrs.org
Using this form of the compound, J.L. Atwood and colleagues from the University of Missouri-Columbia together with L.B. Barbour from the University of Stellenbosch, South Africa, have demonstrated its ability to absorb methane at standard conditions of temperature and pressure, as they explained in the January issue of Chemistry Communications (p. 51; DOI: 10.1039/b416752j).

The investigators constructed a system to measure gas sorption, composed of two chambers joined by modular brass components with valves for isolating and regulating pressure and electronic transducers on each chamber to measure pressure. By placing it in an insulated enclosure, the researchers were able to maintain the system at a constant temperature during testing. First, the research team placed $1.4 \mathrm{~g}$ of sublimed powders of $p$-tert-butylcalix[4]arene in one chamber (volume $=12.6 \mathrm{~cm}^{3}$ ) and vacuum-sealed the system, closing all valves to isolate each chamber. Then, they filled the other chamber (volume = $15.4 \mathrm{~cm}^{3}$ ) with methane to a pressure of 1503 Torr, and later allowed the pressure in both chambers to balance, opening the communicating valve for $1 \mathrm{~s}$ and then closing it. At this point, the recorded pressure in the chamber containing the $p$-tert-butylcalix[4]arene powders started to decrease continuously, until it reached equilibrium after $2.5 \mathrm{~h}$. The corresponding pressure measured was 410 Torr, giving a molar ratio of $0.14: 1$ methane to calixarene.

A rigid model of the crystalline structure of $p$-tertbutylcalix[4]arene shows this compound as a pair of concave molecules in front of each other but slightly off, containing a $235 \AA^{3}$ cavity, thus forming a capsule with seemingly nonporous walls, which would prevent gas adsorption. In order to explain the occurrence of gas adsorption, the researchers analyzed the solid-state model of the p-tert-butylcalix[4]arene structure: finding that the tert-butyl groups of the molecule could rotate around the $\mathrm{C}(\mathrm{ar})-\mathrm{C}\left(s p^{3}\right)$ bond, while the aromatic and hydroxyl regions remained static. The proposed interpretation of the results is based on the existence of windows of opportunity created by the cooperative rotation of these groups, which the gas molecules use to gain entrance to the $p$-tert-butylcalix[4]arene cavity. This study demonstrated that methane represents the optimal occupation of available space, since the compound cavity can accommodate two molecules of the methane instead of just one for $\mathrm{CO}_{2}$. Calculations from the results demonstrated that $14 \%$ of the capsules thus formed contain two molecules of methane at $0.54 \mathrm{~atm}$ on average. So long as the $p$-tert-butylcalix[4]arene remains low density, said the researchers, its potential as a sorbant for volatile gases qualifies it as a viable gas-storage substrate.

SIARI SOSA

\section{Far-Field Raman Scattering Reveals Surface Plasmons of Gold Nanoparticle Arrays}

Surface plasmons are collective excitations of conduction electrons that are excited by the interaction of an electromagnetic field (light) with a metal surface. When the size of the metal particles is much smaller (i.e., nanoparticles) than the characteristic wavelength of the impinging light wavelength, the surface plasmon is at the same time an excited electronic state localized on the particle surface and a local polariton mode of the electromagnetic field. In both cases, the surface plasmon is accompanied by an enhancement of the electromagnetic field, which has opened new applications in subwavelength optics and high-sensitivity spectroscopy (i.e., surface-enhanced Raman scattering, or SERS). In the February 9 issue of NanoLetters (p. 253; DOI: $10.1021 / \mathrm{nl} 048234 \mathrm{u}$ ), in a joint collaboration, G. Laurent (Université de Paris 7), J.R. Krenn (Karl Franzens Universität, Austria), and their colleagues have recorded images of localized surface plasmons using Raman scattering of a molecular probe (methylene blue, MB) adsorbed on regular arrays of gold nanoparticles.

SERS spectroscopy has demonstrated that only a few particles are responsible for the Raman signal of a molecular probe adsorbed on silver or gold nanoparticles deposited on a substrate. These active 


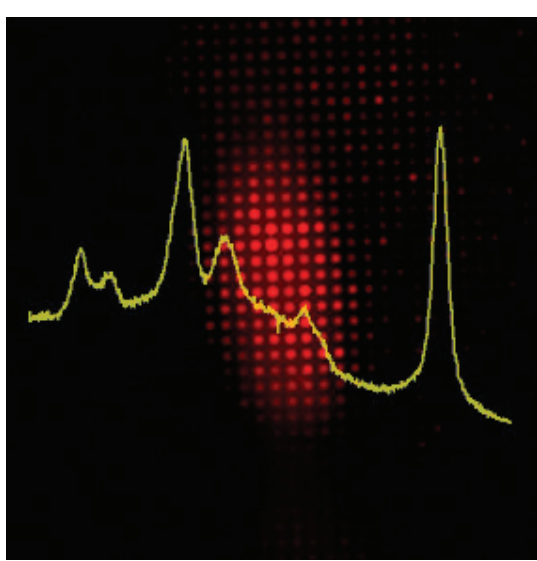

Figure 1. Raman scattering spectrum of methylene blue dye adsorbed as a single layer on a regular array of

105-nm-diameter and 45-nm-high gold nanospheroids spaced by $1 \mu \mathrm{m}$ in the $1300-1700 \mathrm{~cm}^{-1}$ spectral trum is the Raman scattering image of the same array, showing that the scattering arises from molecules that the intensity distribution follows the Gaussian intensity distribution of the incident laser beam. Reprinted with permission from NanoLetters 5 (2005), DOI: 10.1021/nl048234u. (c) 2005 American Chemical Society. region. The background of this specadsorbed on the nanoparticles and

sites were designed as hot spots. Laurent, Krenn, and their colleagues explored whether such spots also appear when nanoparticles are arranged in regular arrays. The researchers further studied the possibility of using enhanced Raman scattering as a technique for their research on plasmon properties.

The researchers investigated two arrays. The first consisted of spheroidal oblate gold particles of $105 \mathrm{~nm}$ circular section parallel to the substrate, $45 \mathrm{~nm}$ high and with $1 \mu \mathrm{m}$ interparticle spacing. The second consisted of elongated gold particles (long axis, $210 \mathrm{~nm}$; short axis, $105 \mathrm{~nm}$; and height $45 \mathrm{~nm}$ ) spaced by $2 \mu \mathrm{m}$. In their experimental setup, the localized surface plasmons were excited by total internal reflection using the $647 \mathrm{~nm}$ wavelength of an ArKr laser. The polarized laser beam was coupled to a polarization-preserving singlemode fiber optic and then focused at the grating air interface; due to the internal reflection setup, the focused laser spot at the array had an elliptical shape of $\sim 20 \mu \mathrm{m}$ (long axis) $\times 10 \mu \mathrm{m}$ (short axis). The elastic and Raman signals were collected with a microscope objective and sent through a rotating mirror alternately to the entrance slit of the spectrometer or to the CCD camera. Various long-pass filters set on the camera optical path enabled the rejection of elastic scattering (and all wavelengths shorter than $670 \mathrm{~nm}$ ) by a factor of $10^{10}$ in transmission.

Raman scattering displayed circular spots that were spaced by the grating constant of the metal nanoparticles (see Figure 1). These spots appeared circular regardless of the particle shape because of the effects of diffraction from spots much smaller than the wavelength The results show that all particles from the array contributed to the Raman spectrum with the same efficiency (i.e., that no hot spots were observed), in contrast to those obtained on a disorganized substrate in which only a few particles among many were SERS-active. This is in agreement with recent computations that show that hot spots appear at the junction of two particles.

According to the researchers, these results demonstrate that surface-enhanced Raman scattering can be a powerful technique for studying plasmonic crystals in which some defects can localize or guide plasmon modes, thus allowing the storage or transport of information using nanodevices.

ROSALÍA SERNA

FOR MORE RESEARCH NEWS ON MATERIALS SCIENCE . .

access the Materials Research Society Web site: www. mrs.org/connections

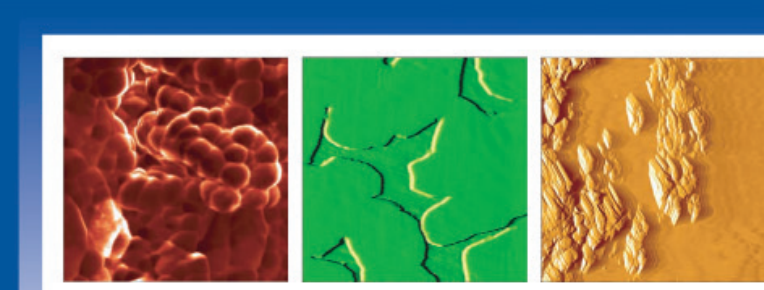

Nano-R ${ }^{\text {TM }}$ AFM

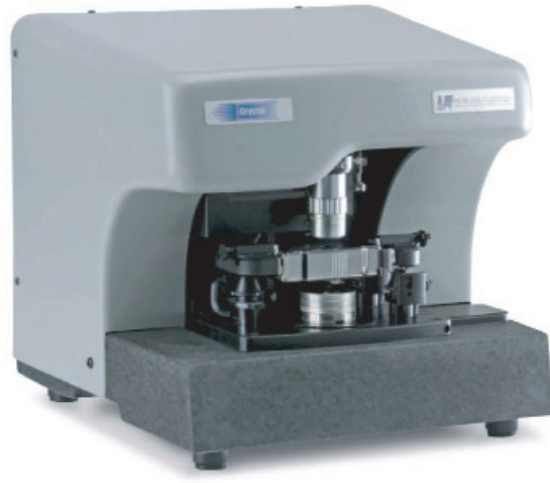

- High Performance

- Easy to Use

- Versatile

Nano- $\mathbf{R}^{\mathrm{TM}}$ is available with a traditional light lever scanner and the advanced Crystal Scanner ${ }^{\mathrm{TM}}$.

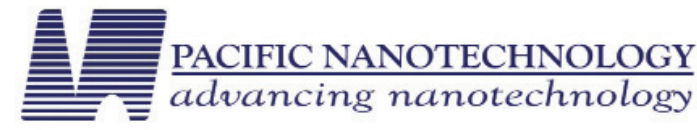

3350 Scott Blvd. \#29

Santa Clara, CA 95054

408-982-9492

www.pacificnanotech.com www.probestore.com
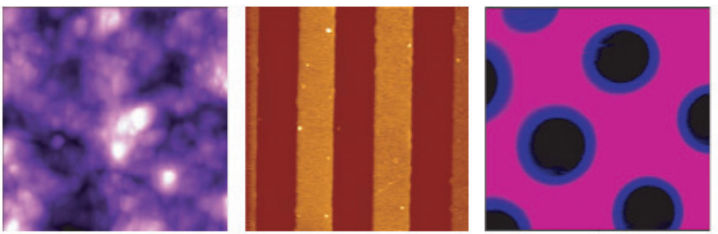


\section{News of MRS Members/Materials Researchers}

S.V. Babu, director of Clarkson University's Center for Advanced Materials Processing (CAMP) and former vice provost of research, has been honored with the title of Distinguished University Professor by the Clarkson University Board of Trustees.

Naomi Halas and Jennifer West of Rice University have each been selected as runners-up for the 2004 Small Times Magazine Best of Small Tech Researcher Award, in recognition of their research toward the development of a novel treatment for cancer using metallic nanoshells.

Gary F. Hawkins has been selected to be principal director of the Space Materials Laboratory at the Aerospace Corporation in Los Angeles.

Nitin P. Padture has joined the faculty of the Department of Materials Science and Engineering at The Ohio State University.

James B. Roberto, associate director for physical sciences at Oak Ridge National Laboratory, received the National Materials Advancement Award from the Federation of Materials Societies on December 8, 2004.

John Rogers, of the University of Illinois at Urbana-Champaign, has been selected as runner-up for the 2004 Small Times Magazine Best of Small Tech Researcher Award. Small Times Media is a leading source of business news and information about nanotechnology, microelectromechanical systems, and microsystems.

Della M. Roy, professor emerita of materials at The Pennsylvania State University, has been honored with the Albert V. Bleininger Memorial Award for distinguished achievement in the field

The American Association for the Advancement of Science has announced fellows elected in 2004, including:

Robert J. Hamers, University of Wisconsin, Madison; Bruce E. Koel, University of Southern California; Eugene E. Haller, University of California-Berkeley; Rodney C. Ewing, University of Michigan, Ann Arbor; Lura J. Powell, Advanced Imaging Technologies, Richland, Wash.; Michael J. Aziz, Harvard University; Leonard C. Feldman, Vanderbilt University; and Luz J. Martinez-Miranda, University of Maryland, College Park.

ASM International has named recipients of its 2004 awards program, including:

P. Rama Rao, of the International Advanced Research Centre for Powder Metallurgy and New Materials (ARCI), Hyderabad, India, who received a Dis- of ceramics by the Pittsburgh Section of the American Ceramics Society.

Ivan K. Schuller, of the University of California, San Diego, has received the 2004 E.O. Lawrence Award in materials research in recognition of outstanding contributions in the broadly defined field of atomic energy.

Amra Tabakovic, an undergraduate materials science and engineering student at The Pennsylvania State University, is the recipient of the J. Earl Frazier Memorial Scholarship by the Pittsburgh Section of the American Ceramics Society.

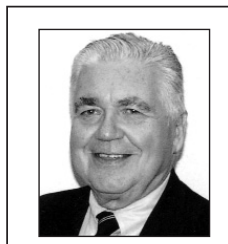

\section{In Memoriam}

Howard K. Birnbaum, 72, of Champaign, Ill., professor emeritus in materials science and engineering at the University of Illinois at UrbanaChampaign (UIUC), passed away on January 23, 2005. He is survived by his wife, Freda; his three children, Elisa, Scott, and Shari; his grandchildren, Aaron, Samuel, Zachary, and Hannah; and his sister, Sybil Licht.

Howard was born October 18, 1932, in Brooklyn, N.Y. He received his BS (1953) and MS (1955) degrees in metallurgy from Columbia University and his PhD degree (1958) in metallurgy from UIUC. He began teaching at the University of Chicago in 1958, joined the faculty at UIUC as an associate professor of metallurgy in 1961, and became director of the Frederick Seitz Materials Research Laboratory (FSMRL) in 1987. Howard officially retired in 1999, but remained active in the scientific community. Howard's research focused on how mechanical deformation and plastic flow in materials derive from the complex interaction of point, line, and planar defects. His early work showed how point defects caused yield effects, provided insight to dislocation core structures, determined interaction energies of point defects and obstacles, and demonstrated that hydrogen diffusion at low temperature occurs by quantum tunneling. His later work focused on hydrogen effects in metals, including hydrogen diffusion, hydrogen trapping, hydrogen ordering, and hydrogen embrittlement mechanisms. Howard's honors included a Guggenheim fellowship, the Mehl Gold Medal from AIME, the Von Hippel Award from the Materials Research Society, and the Department of Energy award for outstanding research and for sustained scientific contributions. He was a member of the National Academy of Engineering and a fellow of the American Academy of Arts and Sciences, the American Physical Society, the American Society for Metals, and The Minerals, Metals \& Materials Society.

Howard's contributions to science and engineering extend well beyond the scientific papers he published. He was a mentor, teacher, and role model for his many graduate students, postdoctoral fellows, and faculty colleagues. He inspired and challenged them to become better scientists, engineers, and citizens. He influenced the direction of science locally through his leadership of the FSMRL and nationally through his involvement on committees, panels, and advisory boards. Howard never shied away from difficult or controversial issues and was an effective spokesperson for science and engineering. He enjoyed discussing science and debating scientific policy, and although these debates could become rather heated, they were always conducted with a sense of good humor.

Howard will be missed not only for his scientific contributions and leadership, but for his humor, wit, and friendship.

IAN ROBERTSON

University of Illinois at Urbana-Champaign

tinguished Life Membership for "outstanding contributions to the metallurgical profession as an educator, researcher, and international policymaker";

Bhakta B. Rath, of the Naval Research Laboratory, Washington, D.C,. who received a Gold Medal for "outstanding contributions in solid-state transformations, microstructure-property relationships, and for visionary leadership in directing leading-edge research for national security";

En Ma, of the Johns Hopkins University, who received the Materials Science Research Silver Medal for "important experimental and theoretical contributions in the study of metastable and nanocrystalline materials";

Subra Suresh of the Massachusetts Institute of Technology, who received the Albert Sauveur Achievement Award for "outstanding contributions to the understanding of deformation behavior at different length scales and mechanics of materials and demonstrated leadership in materials education"; and

Charles J. McMahon of the University of Pennsylvania, Philadelphia, who received the Albert Easton White Distinguished Teacher Award for his "commitment to educating and inspiring both graduate and undergraduate students, and for innovative development of new computer-enhanced tutorial techniques that greatly enhance the learning process."

ASM International announced fellows elected in 2004, including Brent L. Adams, Brigham Young University, Provo, Utah; Indranath Dutta, Naval Postgraduate School, Monterey, Calif.; and Pierre Fauchais, University of Limoges, France. 